J. Clin. Chem. Clin. Biochem.

Vol. 26, 1988, pp. 679-684

(C) 1988 Walter de Gruyter \& Co.

Berlin - New York

\title{
Hormonal Regulation of Glycogen Synthase and Phosphorylase Activities in Human Polymorphonuclear Leukocytes
}

\author{
By Yoshinori Ohtsuka, Takahito Kondo and Yoshikazu Kawakami \\ First Department of Medicine, Hokkaido University School of Medicine, Sapporo 060, Japan
}

(Received April 7/August 16, 1988)

Summary: Hormonal regulation of glycogen synthase and phosphorylase activities were studied in human polymorphonuclear leukocytes. Polymorphonuclear leukocytes from normal subjects were incubated with glucose, insulin, $D, L$-isoproterenol and $L$-thyroxine, either independently or in different combinations, and changes of the enzyme activity ratios of glycogen synthase (active form (I) / total activity (T)) and glycogen phosphorylase (active form (a) / total activity (T)) were assessed.

Neither glucose nor insulin changed the glycogen synthase activity ratio. However, the proportion of the active form (I) of glycogen synthase was increased by the simultaneous addition of glucose and insulin to the incubation mixture, but $D, L$-isoproterenol or $L$-thyroxine diminished this effect and caused a decrease in the proportion of the active form of glycogen synthase.

Insulin had no effect on the glycogen phosphorylase activity ratio. Glucose decreased the proportion of phosphorylase in the a form. The simultaneous addition of glucose and insulin caused no further changes, whereas in the presence of $D, L$-isoproterenol or $L$-thyroxine, this glucose effect was abolished and the proportion of phosphorylase a increased.

These results show that both thyroid hormone and a $\beta$-agonist alter glycogen metabolism to reduce glycogen storage in polymorphonuclear leukocytes.

\section{Introduction}

Glycogen synthase (UDP-glucose: glycogen $4 \alpha-D$-glucosyl transferase, EC 2.4.1.11) is a rate limiting factor in mammalian glycogenesis and, in consequence, a pivotal point of hormonal control: It exists in an active form (I) and a less active $D$ form which is dependent on glucose-6-phosphate. The total amount of the synthase (T) can be measured in the presence of saturating concentrations of glucose-6-phosphate. The enzyme activity ratio (I/T) thus provides a useful index for following changes in the state of activation of the enzyme (1).

Breakdown of glycogen is limited by the activity of glycogen phosphorylase ( $\alpha-1,4$-glucan : orthophosphate glucosyltransferase, EC 2.4.1.1). The enzyme exists in two forms, phosphorylase a and $b$, and the former is more active than the latter. The fractional activity of glycogen phosphorylase, which is subsequently referred to as "glycogen phosphorylase activity ratio", is calculated from the ratio of phosphorylase a activity to total phosphorylase activity (a/T) (2).

Decreased liver glycogen content and decreased total glycogen synthase activity were observed in hyperthyroid rats treated with $L$-thyroxine for forty days (3). In addition, several hormones such as adrenalin, D.Lisoproterenol, insulin and glucagon are also known to affect glycogen synthase and phosphorylase activities (4-11). However, no study has been reported on the effect of thyroid hormone on these enzymes using human tissue cells. 
In the present study, to investigate the hormonal regulation of these enzyme activities, we carried out the in vitro incubation of human polymorphonuclear leukocytes with glucose, insulin, $D, L$-isoproterenol and $L$-thyroxine, since polymorphonuclear leukocytes are easily available from human tissues and contain a sufficient amount of glycogen (12).

\section{Materials and Methods}

Materials

UDP- $\left[{ }^{14} \mathrm{C}\right]$ glucose (specific activity $11.9 \mathrm{GBq} / \mathrm{mmol}$ ) was purchased from New England Nuclear and $\alpha-D-\left[\mathrm{U}-{ }^{14} \mathrm{C}\right]$ glucose-1phosphate (specific activity $11.6 \mathrm{GBq} / \mathrm{mmol}$ ) was from Amersham International plc. UDP-glucose, glucose-1-phosphate, glucose-6-phosphate, porcine insulin and $D, L$-isoproterenol were from Sigma. $L$-Thyroxine was a generous gift from Takeda Chemical Industry. Ficoll-Hypaque was from Pharmacia. All other reagents were of the highest purity commercially available.

\section{Separation of polymorphonuclear leukocytes}

Twenty $\mathrm{ml}$ of heparinized venous blood was collected from non-diabetic subjects and polymorphonuclear leukocytes were isolated by dextran sedimentation of the erythrocytes and differential centrifugation of the polymorphonuclear leukocytes using Ficoll-Hypaque. Contaminating erythrocytes were haemolysed by $8.7 \mathrm{~g} / 1 \mathrm{NH}_{4} \mathrm{Cl}, \mathrm{pH}$ 7.4. Polymorphonuclear leukocytes were suspended at a concentration of $20 \times 10^{9} / 1$ in a buffer consisting of $50 \mathrm{mmol} / \mathrm{l}$ Tris- $\mathrm{HCl}$ and $5 \mathrm{mmol} / \mathrm{l}$ EDTA, $\mathrm{pH} 7.8(12,13)$.

\section{Glycogen synthase assay}

In the preliminary study, to assess the effect of $L$-thyroxine on glycogen synthase activity, we incubated polymorphonuclear leukocytes with various concentrations of $L$-thyroxine for the indicated times as shown in figure 1. Apparently, the maximal effect of $L$-thyroxine was obtained at the concentration of 3.2 $\mu \mathrm{mol} / \mathrm{l}(\mathrm{A})$ and at the time of $2 \mathrm{~min}(\mathrm{~B})$.

The effect of glucose, insulin and $D, L$-isoproterenol on the glycogen synthase activity was examined as described by $J u h l$ et al. (7) with slight modifications. Briefly, suspensions of polymorphonuclear leukocytes were preincubated in the buffer for $5 \mathrm{~min}$ and then incubated with $30 \mathrm{mmol} / \mathrm{l}$ glucose and/or $1.62 \mathrm{nmol} / 1$ insulin for $4 \mathrm{~min}$, and/or $1 \mu \mathrm{mol} / 1 \mathrm{D}, L$-isoproterenol for $1 \mathrm{~min}$ and/or $3.2 \mu \mathrm{mol} / \mathrm{l} \mathrm{L}$-thyroxine for $2 \mathrm{~min}$ individually and together. All incubations were done at $37^{\circ} \mathrm{C}$. The suspensions were then ultrasonically disrupted with $100 \mathrm{mmol} / \mathrm{l} \mathrm{NaF}$. This crude homogenate was then centrifuged at $10000 \mathrm{~min}^{-1}$ for $5 \mathrm{~min}$ at $4^{\circ} \mathrm{C}$ using a microfuge and the supernatant was assayed with a mixture containing $6.7 \mathrm{mmol} / 1 \mathrm{UDP}-\left[{ }^{14} \mathrm{C}\right]$ glucose and $0.6 \mathrm{mg}$ glycogen, with or without $6.7 \mathrm{mmol} / 1$ glucose- 6 phosphate, for $10 \mathrm{~min}$ at $37^{\circ} \mathrm{C}$ according to the method described by Thomas et al. (1).

\section{Glycogen phosphorylase assay}

Polymorphonuclear leukocytes were incubated with several reagents under the same conditions described above. Incubations were stopped by the addition of MES buffer $(10 \mathrm{mmol} / 1 \mathrm{MES}$ (morpholinoethanesulphonic acid), $50 \mathrm{mmol} / \mathrm{l} \mathrm{NaF}, 25 \mathrm{mmol} / \mathrm{l}$ $\beta$-glyccrophosphate, $10 \mathrm{mmol} / \mathrm{l}$ EDTA containing $0.1 \mathrm{mg}$ digitonin, pH 6.1). Glycogen phosphorylase activity was measured
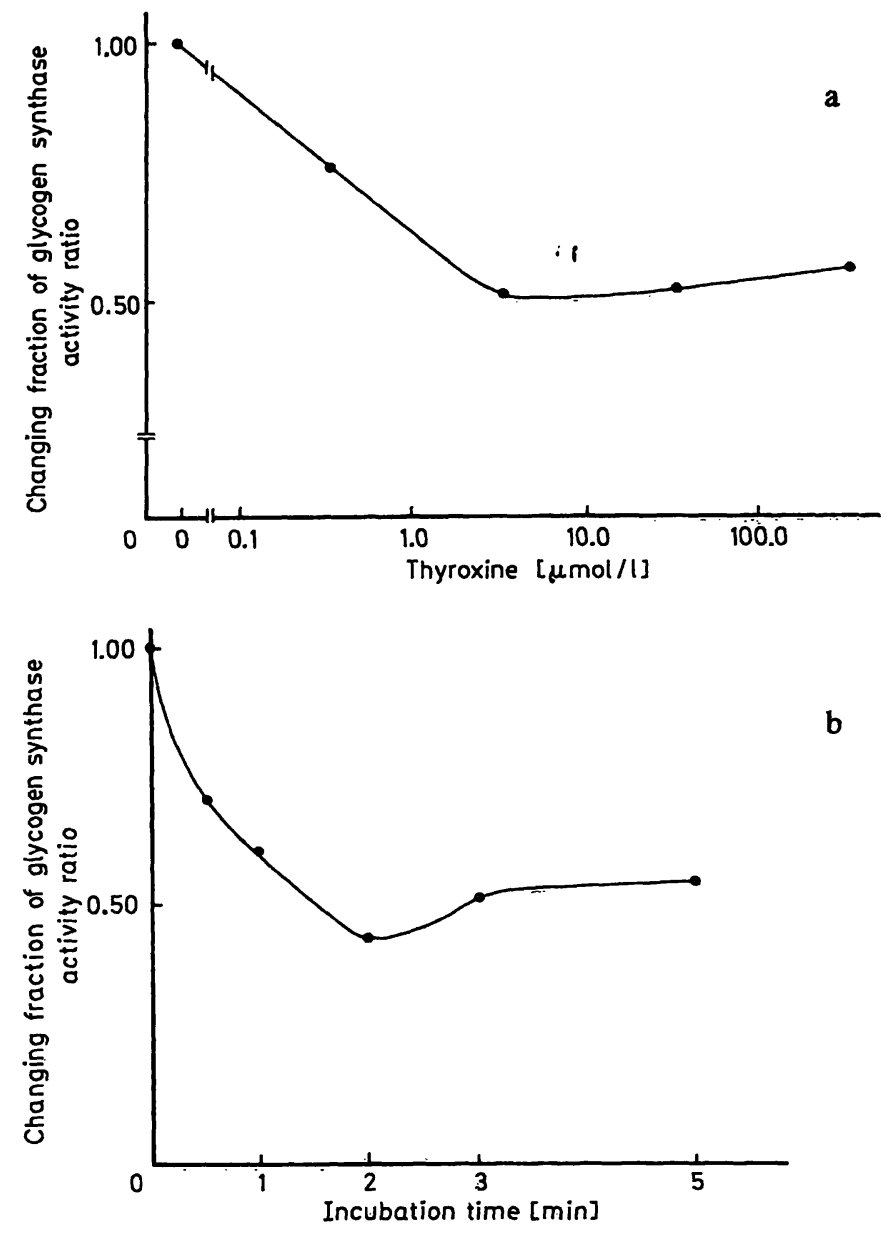

Fig. 1. Effect of $L$-thyroxine on the glycogen synthase activity in human polymorphonuclear leukocytes.

a) Changing fractions of glycogen synthase activity ratio after incubation with $L$-thyroxine for $2 \mathrm{~min}$. Changes of enzyme activity ratio were estimated at various concentrations of $L$-thyroxine. Data are shown as means of four determinations in two separate experiments.

b) Changing fractions of enzyme activity ratio after incubation with $3.2 \mu \mathrm{mol} / 1 \mathrm{~L}$-thyroxine. Changes of enzyme activity ratio were estimated at indicated times. Data represent means of four determinations in two separate experiments.

according to Gilboe et al. (2). Briefly, the enzyme activity was determined in the presence of $20 \mathrm{mmol} / 1$ [ ${ }^{14} \mathrm{C}$ ]glucose-1-phosphate, $10 \mathrm{~g} / \mathrm{l}$ glycogen, $12.5 \mathrm{mmol} / \mathrm{l} \mathrm{NaF}$ with $0.5 \mathrm{mmol} / \mathrm{l}$ caffeine (phosphorylase a activity) or with $3 \mathrm{mmol} / \mathrm{l}$ AMP (total phosphorylase activity).

\section{Statistical analysis}

Statistical differences between the groups were established with Student's t test. Results are presented as mean \pm SD.

\section{Results}

Changes of glycogen synthase and phosphorylase activity ratios are summarized in table 1 and 2, respectively. The effect of glucose and insulin on the glycogen synthase activity ratio is graphed in figure 2 . 
Tab. 1. Changes of glycogen synthase activity (fraction of $I$ ) after incubation with various reagents.

\begin{tabular}{llll}
\hline Effectors & Before & After & Significance \\
\hline Glucose & $0.322 \pm 0.108$ & $0.335 \pm 0.104(6)$ & NS \\
Insulin & $0.290 \pm 0.149$ & $0.282 \pm 0.184(6)$ & $\mathrm{NS}$ \\
Glucose + Insulin & $0.362 \pm 0.100$ & $0.531 \pm 0.129(5)$ & $\mathrm{p}<0.02$ \\
$D, L$-Isoproterenol & $0.415 \pm 0.101$ & $0.246 \pm 0.149(5)$ & $\mathrm{p}<0.05$ \\
$L$-Thyroxine & $0.423 \pm 0.059$ & $0.252 \pm 0.091(5)$ & $\mathrm{p}<0.005$ \\
$D, L$-Isoproterenol + L-Thyroxine & $0.393 \pm 0.103$ & $0.163 \pm 0.117(4)$ & $\mathrm{p}<0.01$ \\
Glucose + Insulin + D,L-Isoproterenol & $0.390 \pm 0.098$ & $0.210 \pm 0.116(7)$ & $\mathrm{p}<0.001$ \\
Glucose + Insulin + L-Thyroxine & $0.434 \pm 0.046$ & $0.237 \pm 0.104(5)$ & $\mathrm{p}<0.005$ \\
\hline
\end{tabular}

Results are expressed as means $\pm \mathrm{SD}$, with the number of experiments in parentheses. Statistically significant with respect to preincubation values.

Tab. 2. Changes of glycogen phosphorylase activity (fraction of a) after incubation with various reagents.

\begin{tabular}{llll}
\hline Effectors & Before & After & Significance \\
\hline Glucose & $0.472 \pm 0.044$ & $0.343 \pm 0.026(4)$ & $\mathrm{p}<0.005$ \\
Insulin & $0.452 \pm 0.045$ & $0.466 \pm 0.051(6)$ & $\mathrm{NS}$ \\
$D, L$-Isoproterenol & $0.442 \pm 0.051$ & $0.606 \pm 0.088(4)$ & $\mathrm{p}<0.02$ \\
$L$-Thyroxine & $0.434 \pm 0.065$ & $0.553 \pm 0.083(5)$ & $\mathrm{p}<0.02$ \\
Glucose $+D, L$-Isoproterenol & $0.378 \pm 0.024$ & $0.504 \pm 0.019(4)$ & $\mathrm{p}<0.005$ \\
Glucose $+L$-Thyroxine & $0.388 \pm 0.014$ & $0.493 \pm 0.019(3)$ & $\mathrm{p}<0.02$ \\
\hline
\end{tabular}

Results are expressed as means $\pm \mathrm{SD}$, with the number of experiments in parentheses. Statistically significant with respect to preincubation values.
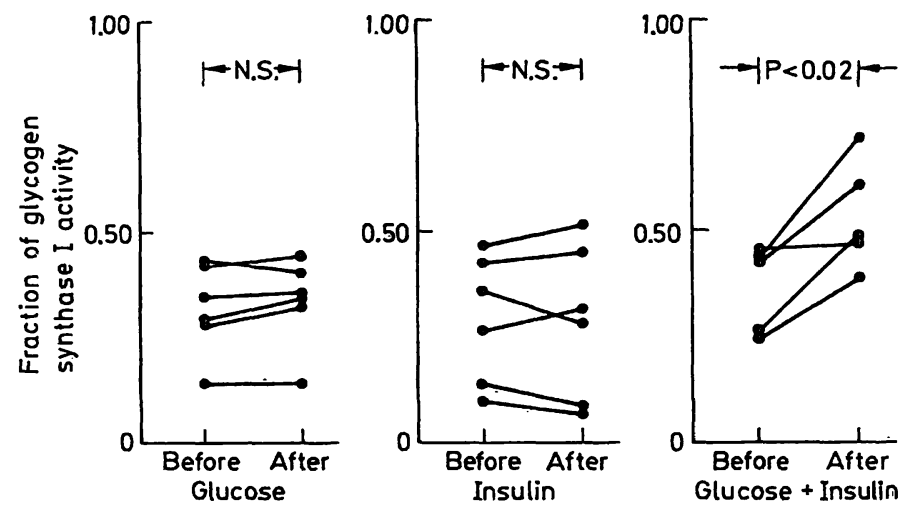

Fig. 2. Effect of glucose and insulin on the glycogen synthase activity in human polymorphonuclear leukocytes. Cells were incubated with $30 \mathrm{mmol} / \mathrm{l}$ glucose and/or 1.62 nmol/1 insulin for $4 \mathrm{~min}$ at $37^{\circ} \mathrm{C}$. The fractions of synthase I were measured before and after the incubation.

The proportions of glycogen synthase I were 0.322 \pm 0.108 and $0.335 \pm 0.104$, before and after treatment with glucose, respectively. By treatment with insulin, the values of synthase I were changed from $0.290 \pm 0.149$ to $0.282 \pm 0.184$. From these data, neither glucose nor insulin had an apparent effect on the enzyme activity ratio. When polymorphonuclear leukocytes were incubated with both glucose and insulin, the values for synthase I increased from 0.362 \pm 0.100 to $0.531 \pm 0.129(\mathrm{p}<0.02)$. Figure 3 shows the changes in the proportion of glycogen synthase I after incubation with $D, L$-isoproterenol or $L$-thyroxine. Both reagents caused the enzyme activity ratio to decrease. Treatment with $D, L$-isoproterenol decreased the values for synthase I from $0.415 \pm 0.101$ to 0.246 $\pm 0.149(\mathrm{p}<0.05)$. With $L$-thyroxine treatment, the values for synthase I decreased from $0.423 \pm 0.059$ to $0.252 \pm 0.091(\mathrm{p}<0.005)$. When polymorphonuclear leukocytes were incubated with $D, L$-isoproterenol and $L$-thyroxine at the same time, a slightly

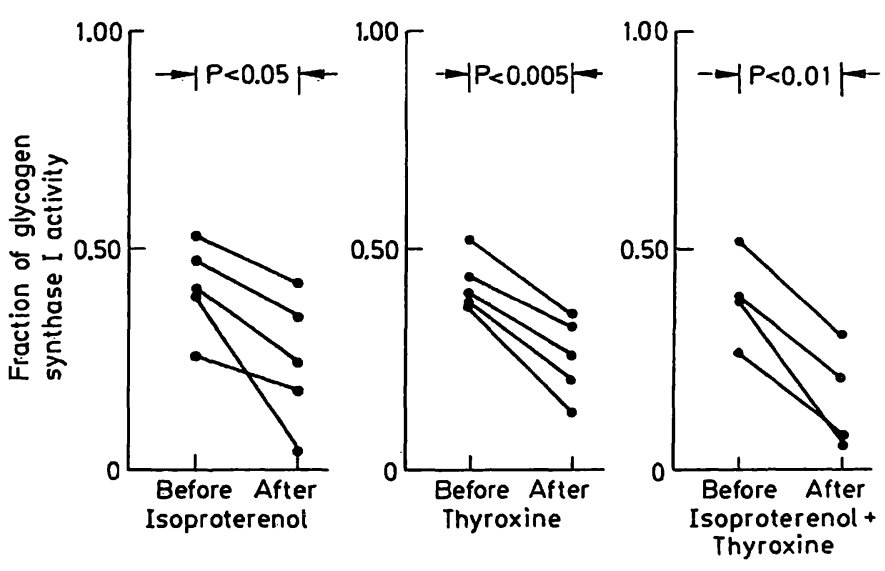

Fig. 3. Effect of $D, L$-isoproterenol and $L$-thyroxine on the glucogen synthase activity in human polymorphonuclear leukocytes. Cells were incubated with $1 \mu \mathrm{mol} / 1 \mathrm{D}, L$ isoproterenol for $1 \mathrm{~min}$ and/or $3.2 \mu \mathrm{mol} / 1 L$-thyroxine for $2 \mathrm{~min}$ at $37^{\circ} \mathrm{C}$. The fractions of synthase I were measured before and after the incubation. 

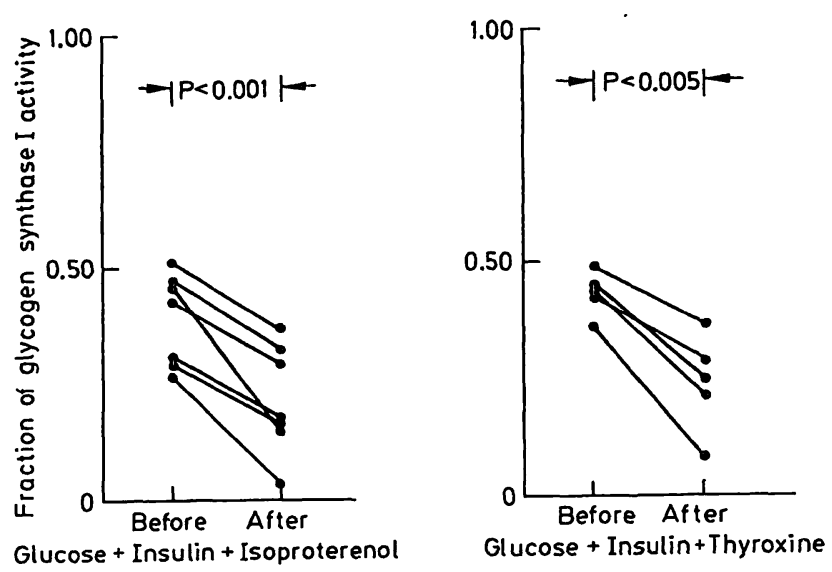

Fig. 4. Effect of $D, L$-isoproterenol and $L$-thyroxine on the fractions of synthase I increased by glucose plus insulin. Cells were incubated with $30 \mathrm{mmol} / \mathrm{l}$ glucose plus 1.62 $\mathrm{nmol} / \mathrm{l}$ insulin and $1 \mu \mathrm{mol} / \mathrm{l} D, L$-isoproterenol or 3.2 $\mu \mathrm{mol} / \mathrm{l} L$-thyroxine for $4 \mathrm{~min}$ at $37^{\circ} \mathrm{C}$. The fractions of synthase I were measured before and after the incubation.
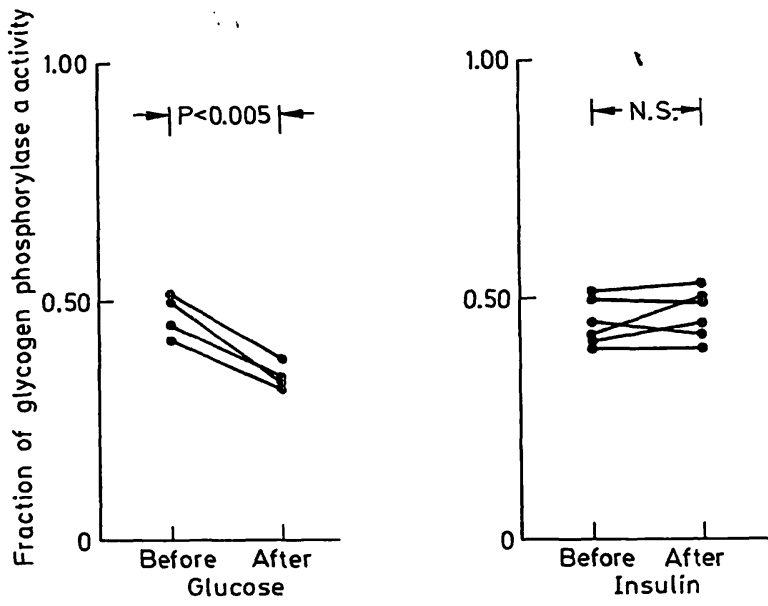

Fig. 5. Effect of glucose and insulin on the glycogen phosphorylase activity in human polymorphonuclear leukocytes. Incubations were done under the same conditions as described in fig. 2. The fractions of phosphorylase a were measured before and after the incubation.

augmented decrease in the values for synthase I were observed: $0.393 \pm 0.103$ and $0.163 \pm 0.117$ before and after treatment, respectively $(\mathrm{p}<0.01)$. Then we examined the effects of $D, L$-isoproterenol and $L$-thyroxine on the upward changes of the enzyme activity ratio induced by glucose plus insulin. Both $D, L$-isoproterenol and $L$-thyroxine decreased the enzyme activity ratio, which would normally be increased by simultaneous incubation with glucose and insulin (fig. 4). $D, L$-isoproterenol decreased the values for synthase I from $0.390 \pm 0.098$ to $0.210 \pm 0.116$ (p < 0.001). $L$-Thyroxine treatment caused the values for synthase $I$ to decrease from $0.434 \pm 0.046$ to 0.237 $\pm 0.104(\mathrm{p}<0.005)$.
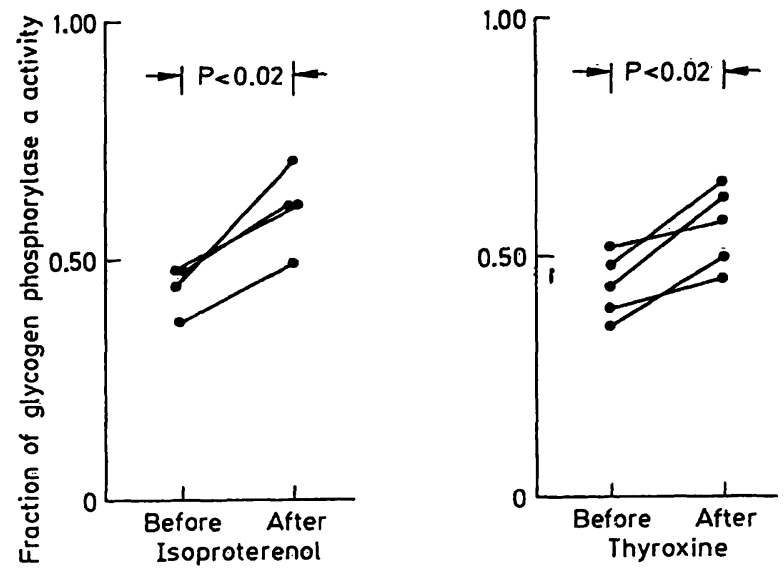

Fig. 6. Effect of $D, L$-isoproterenol and $L$-thyroxine on the glycogen phosphorylase activity in human polymorphonuclear leukocytes. Incubations were done under the same conditions as described in fig. 3. The fractions of phosphorylase a were measured before and after the incubation.
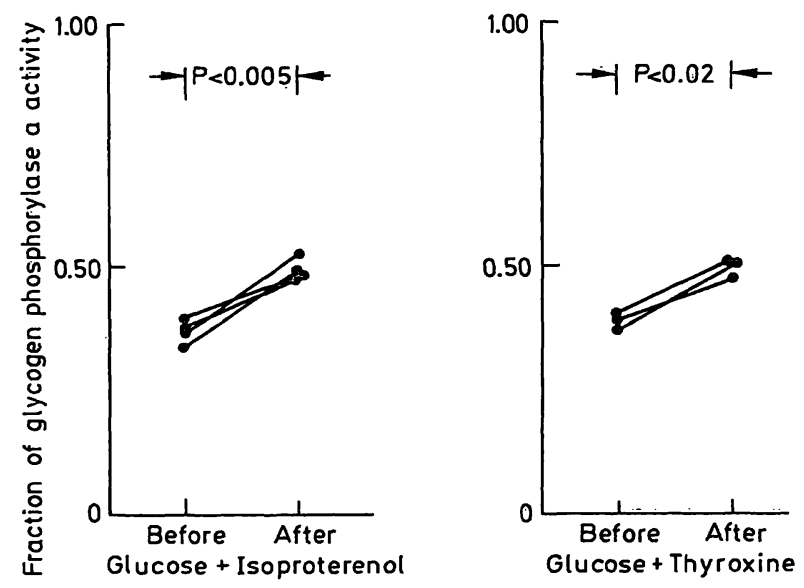

Fig. 7. Effect of glucose plus $D, L$-isoproterenol and glucose plus $L$-thyroxine on the glycogen phosphorylase activity in human polymorphonuclear leukocytes. Incubations were done for $4 \mathrm{~min}$ at $37^{\circ} \mathrm{C}$. The fractions of phosphorylase a were measured before and after the incubation.

Figure 5 shows the effect of glucose and insulin on the glycogen phosphorylase activity ratio. Insulin had no effect on the glycogen phosphorylase activity ratio, but glucose apparently decreased the enzyme activity ratio. The values for phosphorylase a decreased from $0.472 \pm 0.044$ to $0.343 \pm 0.026(p<0.005)$. Glucose plus insulin showed no further changes of the enzyme activity ratio (data not shown). $D, L$-isoproterenol and $\dot{L}$-thyroxine increased the enzyme activity ratio (fig. 6). By treatment with $D, L$-isoproterenol, the values for phosphorylase a increased from $0.442 \pm 0.051$ to $0.606 \pm 0.088(\mathrm{p}<0.02)$. With $L$-thyroxine treatment, the values for phosphorylase a increased from $0.434 \pm 0.065$ to $0.553 \pm 0.083(p<0.02)$. When 
polymorphonuclear leukocytes were incubated with glucose and $D, L$-isoproterenol at the same time, the decrease observed in the presence of glucose was abolished, and the values for phosphorylase a increased from $0.378 \pm 0.024$ to $0.504 \pm 0.019$ (fig. 7, $\mathrm{p}<0.005)$. Incubation with glucose and $L$-thyroxine simultaneously produced similar results, and the values for phosphorylase a increased from $0.388 \pm 0.014$ to $0.493 \pm 0.019$ (fig. $7, \mathrm{p}<0.02$ )

\section{Discussion}

Impaired glucose tolerance is frequently observed in hyperthyroid patients (14-16). Glucose intolerance has been ascribed to rapid gastric emptying and absorption of nutrients as well as increased splanchnic gluconeogenic precursors and glycogenolytic turnover rates $(16-18)$, but the precise mechanisms leading to glucose intolerance are not understood.

We studied in vitro effects of glucose, insulin, $D, L$ isoproterenol and $L$-thyroxine, on glycogen synthase and phosphorylase activities in polymorphonuclear leukocytes. The levels of these compounds are thought to change in hyperthyroidism. Glucose and insulin are reported to increase the glycogen synthase activity ratio in several animal tissues $(4,8-10,19-21)$. On the other hand, only a few experiments using human tissues have been reported. Insulin was reported to have no effect on the glycogen synthase activity ratio in human polymorphonuclear leukocytes (6). Our data show that neither insulin nor glucose had any effect on the glycogen synthase activity ratio; however, when polymorphonuclear leukocytes were incubated with both of these compounds simultaneously, the enzyme activity ratio increased. These results indicate that in human polymorphonuclear leukocytes glucose must be present in order for insulin to increase the glycogen synthase activity ratio.

Insulin had no effect on glycogen phosphorylase activity in rat tissue cells $(10,19)$; however, Hartmann et al. reported that insulin decreased the basal and the glucagon-activated glycogen phosphorylase activity ratio in rat hepatocyte cultures (22). In human skeletal muscle neither insulin nor glucose changed glycogen phossphorylase activity (23). In human polymorphonuclear leukocytes, glucose was reported to decrease the glycogen phosphorylase activity ratio (7) and this is in accordance with our results. But there is no report concerning the effect of insulin on glycogen phosphorylase activity in human polymorphonuclear leukocytes. In our experiments insulin had no effect on glycogen phosphorylase activity. Insulin- insensitive glycogen synthase and phosphorylase activities in human polymorphonuclear leukocytes may explain the findings of Esmann er al. that insulin had no effect on the glycogen content of normal human polymorphonuclear leukocytes (12).

Little is known about the effect of thyroid hormone on the control of glycogen metabolism in human polymorphonuclear leukocytes. To assess the effect of hyperthyroxinaemia on the glycogen synthase and glycogen phosphorylase activity ratios, we incubated polymorphonuclear leukocytes in vitro with $L$-thyroxine. A decrease of the glycogen synthase and an increase of the glycogen phosphorylase activity ratios were observed. It is suggested that an excess of $L$-thyroxine alters these enzyme activities in polymorphonuclear leukocytes.

Epinephrine and $D, L$-isoproterenol were reported to decrease the glycogen synthase activity ratio $(4,9,11$, $19,20)$ and to increase the glycogen phosphorylase activity ratio $(19,24)$ in animal tissues. Juhl et al. (7) reported that $D, L$-isoproterenol did not change the glycogen synthase activity ratio but increased the glycogen phosphorylase activity ratio in human polymorphonuclear leukocytes. In our experiments $D, L$ isoproterenol decreased the glycogen synthase activity ratio and increased the glycogen phosphorylase activity ratio. These other authors reported a basal glycogen synthase activity ratio which was very much lower than our values, and they probably could not detect the apparent changes in glycogen synthase activity without evaluating the phosphorylation of this enzyme.

Next we examined the effect of $D, L$-isoproterenol and $L$-thyroxine on the glycogen synthase activity ratio stimulated by glucose plus insulin. Both $D, L$-isoproterenol and $L$-thyroxine diminished the glycogen synthase activity ratio which should have been enhanced by glucose plus insulin. Lawrence et al. (9) reported that in rat adipocytes insulin prevented $D, L$-isoproterenol from reducing the glycogen synthase activity ratio. This blocking action means that $D, L$-isoproterenol blocked the ability of insulin to increase the glycogen synthase activity ratio. Our results show that, in human polymorphonuclear leukocytes, not only $D, L$-isoproterenol but also $L$-thyroxine can decrease the glycogen synthase activity ratio, which is known to be increased by simultaneous incubation with glucose and insulin. We also examined the effect of $D, L$-isoproterenol and $L$-thyroxine on the glycogen phosphorylase activity ratio suppressed by glucose. Both reagents increased the glycogen phosphorylase activity ratio which should have been decreased by glucose. 
In conclusion, suppression of glycogen synthase and enhancement of glycogen phosphorylase activities by thyroid hormone and a $\beta$-agonist impair the glycogen metabolism in human polymorphonuclear leukocytes. Although the present study shows the acute effects of thyroid hormone and a $\beta$-agonist, if similar alterations of these enzyme activities are observed in other human tissues, they may have some relations to glucose intolerance among hyperthyroid patients. The study of glycogen metabolism in polymorphonuclear leukocytes appears to be a useful method for elucidating the impaired glucose tolerance in hyperthyroidism.

\section{References}

1. Thomas, J. A., Schlender, K. K. \& Larner, J. (1986) Anal. Biochem. 25, 486-499.

2. Gilboe, D. P., Larson, K. L. \& Nuttall, F. Q. (1972) Anal. Biochem. 47, 20-27.

3. Remesar, X. \& Alemany, M. (1982) Horm. Metabol. Res. 14, 179-182.

4. Wulf, H. D. \& Hers, H. G. (1968) Eur. J. Biochem. 6, 558564.

5. Gold, A. H. (1970) J. Biol. Chem. 245, 903-905.

6. Wang, P., Plesner, L. \& Esmann, V. (1972) Eur. J. Biochem. 27, 297-300.

7. Juhl, H. \& Borregaard, N. (1981) Biochim. Biophys. Acta $675,101-109$ :

8. Bone, A. J., Younan, S. I. M. \& Colon, J. M: (1984) Horm. Metab. Res. 16, 513-515.

9. Lawrence, J. C. Jr., James, C. \& Hiken, J. F. (1986) J. Biol. Chem. 261, 669-677.

10. Miller, T. B. Jr., Garnache, A. K., Cruz, J. McPherson, K. \& Wolleben, C. (1986) J. Biol. Chem. 261, 785-790.

11. Bosch, F., Ciudad, C. J. \& Guinovart, J. J. (1986) FEBS Lett. 200, 47-50.

12. Esmann, V. (1963) Diabetes 12, 545-549.

13. Boyum, A. (1968) Scand. J. Clin. Lab. Invest. 21, 97

14. Kreines, K., Jett, M. \& Knowles, H. C. Jr. (1965) Diabetes 14, 740-744.

15. Maxon, H. R., Kreines, K. W., Goldsmith, R. E. \& Knowles, H. C. (1975) Arch. Intern. Med. 135, 14771480.

16. Holdworth, C. D. \& Besser, G. M. (1981) Lancet I, 700703.

17. Wahren, J., Wennlund, A., Nilsson, L. H. \& Felig, P. (1981) J. Clin. Invest. 67, 1056-1063.

18. Sandler, M. P., Robinson, R. P., Rabin, D., Lacy, W. W. \& Abumrad, N. N. (1983) J. Clin. Endocrinol. Metab. 56, $479-484$.

19. Ramachandran, C., Angelos, K. L. \& Walsh, D. A. (1982) J. Biol. Chem. 257, 1448-1457.

20. Ramachandran, C., Angelos, K. L. \& Walsh, D. A. (1983) J. Biol. Chem. 258, 13377-13383.

21. Chan, C. P. \& Krebs, E. G. (1985) Proc. Natl. Acad. Sci. U.S. A. $82,4563-4567$.

22. Hartmann, H., Probst, I., Jungermann, K. \& Creutzfeldt, W. (1987) Diabetes 36, 551-555.

23. Yki-Järvinen, H., Mott, D., Young, A. A., Stone, K. \& Bogardus, C. (1987) J. Clin. Invest. 80, 95-100.

24. Steiner, K. E., Stevenson, R. W., Green, D. R. \& Cherrington, A. D. (1985) Metabolism 34, 1020-1023.

Yoshinori Ohtsuka

First Department of Medicine

Hokkaido University School of Medicine Sapporo 060

Japan 